(continued from previous page)

other double line at the end of the table. Long tables should, if possible, be submit ted in a form ready for direct photoreproduction. Photoreproducible tables (including captions) should be typed single-spaced on an electric typewriter with Elite type or an equivalent proportional-spaced typeface, and should be designed to fit in one journal column $(85 \times 250 \mathrm{~mm}$, or $33 / 8 \times 97 / 8$ in. $)$ or across two columns $(175 \times 250 \mathrm{~mm}$, or $7 \times 97 / 8$ in.) Since they will be photoreproduced by a factor of 0.75 , photoreproduction should be anticipated by making the typing-area dimensions of the table 4/3 larger than the final column and page dimensions given above. Detailed instructions for preparing camera-ready tables are available from the Editorial Office.
10. Publication. Publications charges defray a major portion of the cost of the production of this journal. Consequently, authors' institutions or companies are urged to pay a publication charge of $\$ 70$ per printed page, which entitles them to 100 reprints. An appropriate form will be mailed to the author upon acceptance of manuscript.

11. Correspondence. Manuscripts are to be submitted to the Editorial Office, Journal of Materials Research, Xexox Webster Research Center, 800 Phillips Road, 0114/38D, Webster, NY 14580.

No correspondence should be sent to the Editor about proofs, reprints, or publication charges. Authors will be notified by the Editor if their paper has been accepted for publication. Authors will also be notified when their paper is sent to the American Institute of Physics. All subsequent correspondence about a particular paper should be addressed to the Editorial Supervisor, Journal of Materials Research, American Institute of Physics, 335 East 45th St., New York, NY 10017 Reference must be made to the author, journal, and scheduled date of issue.

12. Proofs of Articles will be sent to the author for review and should be returned promptly to the Editorial Supervisor, Journal of Materials Research. A few alterations in proof are unavoidable, but the cost of making exirnsive alterations or of correcting mistakes caused by careless preparation of the manuscript will be charged to the author. Unless corrected proofs are returned punctually, publication of the paper will be delayed.

\title{
MRS-Europe Fall Meeting Program Takes Shape
}

\section{Three Symposia Focus on Advanced Materials Research and Development for Transport}

The three symposia comprising the upcoming 1985 MRS-Europe Fall Meeting in Strasbourg will include contributions from 40 invited speakers and panelists, as well as numerous contributed and poster presentations. The meeting to be held November 26-29 at the Council of Europe, will explore both materials science and engineering aspects of "Advanced Materials Research and Development for Transport."

The meeting will open Tuesday morning with a plenary session addressing recent cooperative efforts in the area of materials research and application for transporation. A panel of five experts from Europe will explore the political as well as the scientific aspects of this trend. Panelists and their topics are:

- J. P. Massué (Scientific Advisor to the Parliamentary Assembly, Strasbourg, France)Recent development of the European Network on Advanced Materials by the Conference of the European Research Ministers - J. G. Wurm (EC, Brussels, Belgium)New EC efforts for R\&D in materials - W. J. G. Bunk (DFVLR, Cologne, West Germany) -Needs for advanced materials $R \& D$ for transportation

- A.-Y. Portnoff (Science et Techniques, Paris, France) - Impact of advanced materials on technological systems

-D. Altenpohl (Alusuisse, Zurich, Switzerland)-Doing more with less primary materials.

\section{Symposium A: Light Metals}

This symposium will address materials science and engineering aspects of advanced light metals for transportation with an emphasis on aluminum alloys. Topics will include: aluminum-lithium, rapid solidification technology and powder metallurgy, alloys for elevated temperature use, and advanced fabrication alloys (superplastic forming, casting, and welding). Some of the invited speakers and their topics are:

- Shiro Sato (Sumitomo Light Metals Industries, Japan) - Present and future of aluminum alloys for transport in Japan

- F. Ostermann (Vereinigte AluminumWerke AG, West Germany)-Criteria for selection of aluminum for modern trains

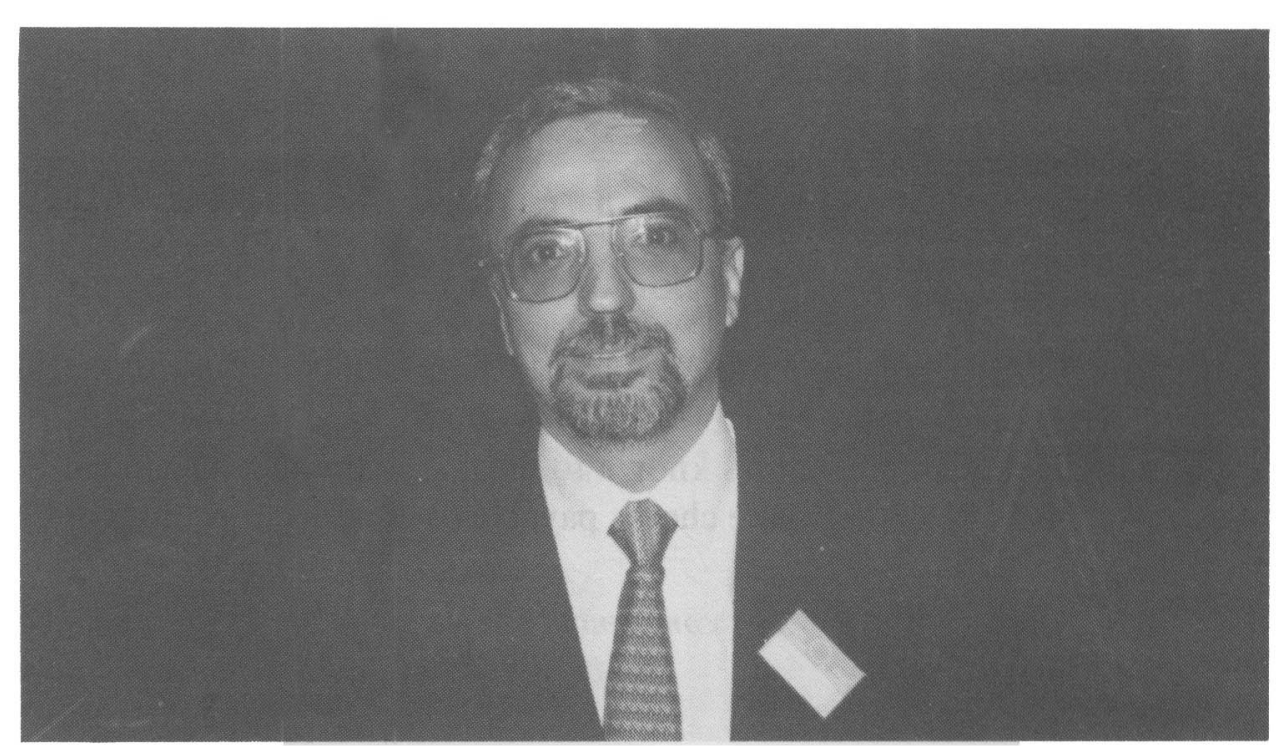

Emanuele Rimini, University of Catania, is a member of the MRS-Europe Organizing

Committee and organizer of IBMM-86.

- P. Kandachar (Fokker Aircraft Factories B.V., The Netherlands)-Applications for advanced aluminum alloys in aircraft

- T. H. Sanders, Jr. (Purdue University, U.S.A.) - Fundamentals of aluminum-lithium alloys

- P. Sainfort (Cegedure Pechiney, France) Basic hardening mechanisms in aluminumlithium alloys

- P. J. Bridges (Inco Alloy Products, UK) An aluminum-lithium alloy made by mechanical alloying

(continued on the next page) 
(continued from previous page)

- B. Evans (Royal Aircraft Establishment, UK)-Engineering aspects of aluminumlithium alloys

- W. S. Miller (Alcan International, UK) RST for high-temperature aluminum alloys - R. F. Singer (Brown Boverie Research Centre, Switzerland) -A review of aluminum alloys RST

- R. Grimes (Alcan International, UK) Superplastic forming of advanced aluminum alloys

- D. Mietrach (Messerschmitt-Bolkow GmbH, West Germany)-Advanced casting in aircarft structures: a way to reduce costs - J. Zehnder (Swiss Aluminum, Ltd., Switzerland)-Applications of aluminum alloys in welded structures.

- E. Di Russo (Alumina Istituto Sperimentale Dei Metalli Leggeri, Italy)-The influence of stress field on the "weld toe cracking" of weld joints of 7000 alloys plates for transport applications

- C. Guillam (Pechiney Electrometallurgie, France)-Supply and demand for magnesium

- W. Unsworth and J. King (Magnesium Elektron Ltd., UK) 一Development of magnesium alloys for structural applications

- N. Hoy-Petersen (Norsk Hydro, Norway) Magnesium on the move

- G. Lüjering Technische Universität Hamburg-Harburg, West Germany)-Fundamental aspects of titanium alloys

- J. P. Herteman (SNECMA, France)Engineering aspects of the use of titanium alloys in the aerospace industry

The symposium chairman is R. J. H. Wanhill, National Aerospace Laboratory, The Netherlands.

\section{Sympsium B: Composites}

Composites applications in transportation in the last decade have enabled lighter and sturdier construction of transportation systems which has resulted in energy savings and increased carrying capacity. This symposium will address these success as well as broader applications for the future.

Topics will include: reinforcing fibers (properties, microstructure, and manufacturing of glass, carbon, aramid, ceramics, etc.), resin composites, metal/ceramic/ carbon-carbon composites, design methodology (economic aspects, durability, reliability, and optimization of fiber-matrix systems), production and processing techniques for large series production, and damage detection and repairing methods. Some of the invited speakers and their topics are:

- H. Kellerer (MBB München, West Germany)-Development of parts and components in the aircraft industry

- A. R. Bunsell (Ecole des Mines, France) Fibers for composite materials

- K. Friedrich (Technical Universität Hamburg-Harburg, West Germany)-Short fiber reinforced thermoplastic resin composites

- R. Naslain (Institut des Materiaux Composites, France) - Ceramic-ceramic composites

- J. J. Lanfranchini (PSA Etudes st Recherches, France)-Processing of composite materials

- M. G. Bader (University of Surrey, UK) Metal matrix composites

- H. Lilholt (Riso National Laboratory, Denmark) -Long-term behavior of composite materials

Symposium chairman is P. Lamicq, Société Européenne de Propulsion, France.

Symposium C: Ceramic Coatings for Heat Engines

This symposium will provide a forum for reviewing that state of the art in the use of cermic systems to protect thermally loded turbines, diesel, and gasoline engines.

Topical sessions are: Monolithic ceramics and ceramic coatings (fundamental aspects, advantages, and disadvantages); engineering requirements and new developments in coatings; interrelation between powder, substrate surface and finishing processes on coating properties; coating evaluation/quality control methods and developments in NDT methods; and industrial applications/performance of coated parts under specific conditions. Some of the invited speakers and their topics are:

- I. Kvernes (I.K. Engineering, Norway)Potential of ceramic coating systems: engineering, materials and process technology aspects

- P. Hancock (Granfield, UK)-Degradation process for ceramic coatings (environmental effets on ceramic coatings)

- D. Rignay (General Electric, USA)Interaction between powders and coating microstructues

- H. A. Crostack (Universität Dortmund, West Germany) NDT nethods fo ceramic coaing systems

- I. Kvernes et al. (I. K. Engineering, Norway)-Performance of thermal barrier coatings in diesel stationary and aircraft gas turbine components: review of preliminary COST 501 results.

Symposium chairman is I.A. Kvernes, I. K. Engineering, Norway.

\section{Registration}

The registration fee for the MRS-Europe Fall Meeting is $1400 \mathrm{FF}$ (400 FF for students). Proceedings of the meeting will be published. For further information, contact $P$. Siffert, MRS-Europe Fall Meeting, Centre de Recherche Nucleaires, Laboratoire PHASE, 67037 Strasbourg Cedex, France; telephone (88) 286543 .

\title{
Plan Now To Take Advantage of
}

\section{JOB PLACEMENT CENTER}

\author{
In Conjunction with 1985 MRS Fall Meeting
}

The Job Placement Center, to be held in conjunction with the 1985 MRS Fall Meeting in Boston (December 2-6), is a valuable way to become acquainted with important contacts in materials research and make your credentials known to them. See the Job Placement Form inside the back cover of this issue. Fee: $\$ 5.00 *$ (Make checks payable to American Institute of Physics).

\author{
A confidential service of the American Institute of Physics \\ on behalf of the Materials Research Society.
}

*Fee for employers is $\$ 60.00$. Contact Beverly Citrynell, AIP, (212) 661-9404 